\title{
Pharyngeal metastasis following living- donor liver transplantation for hepatocellular carcinoma: a case report and literature review
}

Taiji Tohyama ${ }^{1,2^{*}}$, Katsunori Sakamoto ${ }^{1}$, Kei Tamura ${ }^{1}$, Taro Nakamura ${ }^{1}$, Jota Watanabe ${ }^{1}$, Hiroyuki Wakisaka ${ }^{3}$ and Yasutsugu Takada ${ }^{1}$

\begin{abstract}
Background: The most common sites of recurrence after liver transplantation for hepatocellular carcinoma (HCC) have been reported to be the liver, lung, bone, and adrenal glands, but there have also been many reports of cases of multiple recurrence. The prognosis after recurrence is poor, with reported median survival after recurrence of HCC ranging from 9 to 19 months. Here, we report a case of long-term survival after recurrence of pharyngeal metastasis following living-donor liver transplantation (LDLT) for HCC within the Milan criteria, by resection of the metastatic region and cervical lymph node dissection.
\end{abstract}

Case presentation: A 47-year-old man with a Model End-stage Liver Disease (MELD) score of 11 underwent LDLT for HCC within the Milan criteria for liver cirrhosis associated with hepatitis B virus infection, with his 48-year-old elder brother as the living donor. One year and 10 months after liver transplantation, he visited a nearby hospital with a chief complaint of discomfort on swallowing. A pedunculated polyp was found in the hypopharynx, and biopsy revealed HCC metastasis. We performed pharyngeal polypectomy. Two years later, cervical lymph node metastasis appeared, and neck lymph node dissection was performed. Although recurrence subsequently occurred three times in the grafted liver, the patient is still alive 12 years and 10 months after recurrence of pharyngeal metastasis. He is now a tumor-free outpatient taking sorafenib.

Conclusion: It is necessary to recognize that the nasopharyngeal region is a potential site of HCC metastasis. Prognostic improvement can be expected with close follow-up, early detection, and multidisciplinary treatment, including radical resection.

Keywords: Hepatocellular carcinoma, Pharyngeal metastasis, Nasopharynx, Liver transplantation, Vertebral venous plexus

\footnotetext{
*Correspondence: taitoh1128@gmail.com

1 Department of Hepato-Biliary-Pancreatic and Breast Surgery, Ehime

University Graduate School of Medicine, Shitsukawa, Toon, Ehime 791-0295,

Japan

${ }^{2}$ Department of Surgery, Kurashiki Medical Center, Bakuro-cho, Kurashiki,

Okayama 710-8522, Japan

Full list of author information is available at the end of the article
}

(C) The Author(s). 2020 Open Access This article is licensed under a Creative Commons Attribution 4.0 International License, which permits use, sharing, adaptation, distribution and reproduction in any medium or format, as long as you give appropriate credit to the original author(s) and the source, provide a link to the Creative Commons licence, and indicate if changes were made. The images or other third party material in this article are included in the article's Creative Commons licence, unless indicated otherwise in a credit line to the material. If material is not included in the article's Creative Commons licence and your intended use is not permitted by statutory regulation or exceeds the permitted use, you will need to obtain permission directly from the copyright holder. To view a copy of this licence, visit http://creativecommons.org/licenses/by/4.0/. The Creative Commons Public Domain Dedication waiver (http://creativecommons.org/publicdomain/zero/1.0/) applies to the data made available in this article, unless otherwise stated in a credit line to the data. 


\section{Background}

In 1996, Mazzaferro et al. reported that when liver transplantation for hepatocellular carcinoma (HCC) was restricted to patients with early-stage disease (defined as a single tumor less than $5 \mathrm{~cm}$ in diameter, or up to three tumors less than $3 \mathrm{~cm}$ in diameter, without vascular invasion or extrahepatic metastasis), the 4-year survival rate was $75 \%$, similar to survival rates for patients with non-HCC liver disease [1]. These criteria, which were soon termed the "Milan criteria," became the worldwide benchmark for liver transplantation criteria for HCC. The Milan criteria, limiting the indications for liver transplantation for $\mathrm{HCC}$, have reduced the postoperative recurrence rate of $\mathrm{HCC}$. However, $\mathrm{HCC}$ still recurs in $1.6-13 \%$ of recipients within the Milan criteria after liver transplantation [1-6]. There have been many reports of cases with multiple instances of recurrence due to systemic recurrence caused by extra-hepatic circulating tumor cells. The prognosis after recurrence of HCC is poor, with reported median survival ranging from 9 to 19 months in major transplant centers in both Western and Eastern countries [4, 7-12]. However, if the recurrence remains local, such as within the liver, lung, or adrenal gland, surgical resection may improve prognosis, and cases of long-term survival have been reported [4,
$6-8,10,11,13]$. Here, we report a case of long-term survival after resection of the pharyngeal metastasis due to HCC recurrence after living-donor liver transplantation (LDLT).

\section{Case presentation}

A 47-year-old man with a Model End-stage Liver Disease (MELD) score of 11 and liver cirrhosis associated with hepatitis $B$ virus (HBV) infection underwent LDLT for $\mathrm{HCC}$, with his 48-year-old elder brother as the living donor, in November 2004. He had received transarterial chemoembolization (TACE) 5 months before liver transplantation and was assessed as having a partial response according to the modified Response Evaluation Criteria in Solid Tumors (mRECIST) [14]. The patient had no history of other diseases, and there were also no diseases of note in his family history. The right lobe of the donor was harvested and weighed $710 \mathrm{~g}$ (graft-to-recipient weight ratio, 1.09). The donor and recipient had the same blood type. Preoperative abdominal computed tomography (CT) revealed liver cirrhosis with three hypervascular nodules, diagnosed as $\mathrm{HCC}$, which were $2.0,2.5$, and $2.8 \mathrm{~cm}$ in diameter and met the Milan criteria (Fig. 1a). Preoperative tumor marker levels were as follows: $\alpha$-fetoprotein (AFP), $5 \mathrm{ng} / \mathrm{ml}$; and des- -
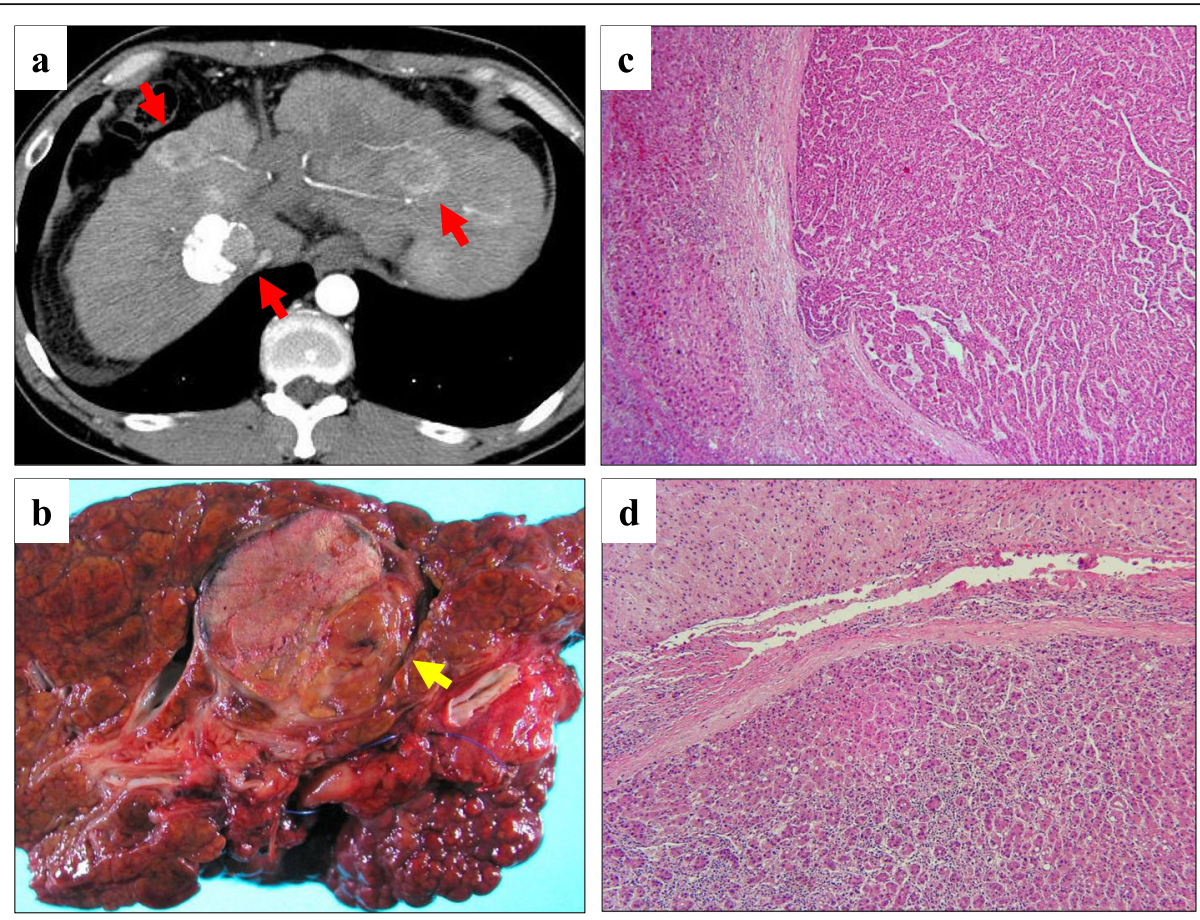

Fig. 1 Computed tomography $(C T)$ images before living-donor liver transplantation and histopathological findings of the resected native liver. a Preoperative abdominal CT showing liver cirrhosis with three hypervascular nodules that were 20, 25, and 28 mm in diameter. Embolism deposits due to transarterial chemoembolization (TACE) were observed in one of the three $\mathrm{S} 1$ tumors. $\mathbf{b}$ Macroscopic examination of the resected liver revealed the presence of a tumor $28 \mathrm{~mm}$ in diameter with partial necrosis due to preoperative TACE in segment 1, but no tumors were observed in other areas, only regenerated nodules. $\mathbf{c}$, d Microscopic view of moderately differentiated hepatocellular carcinoma (HCC) with necrotic changes in segment 1 and multiple well-differentiated HCC lesions with trabecular and pseudoglandular structures measuring a few millimeters in diameter 
carboxy prothrombin (DCP), $327 \mathrm{mAU} / \mathrm{ml}$. Pathological examination of the resected liver revealed one moderately differentiated HCC with necrotic change in a 2.4-cm area, and multiple well-differentiated HCC lesions measuring a few millimeters that appeared to indicate multicentric occurrence. Microvascular invasion was not seen (Fig. 1b, c, d). We used tacrolimus and mycophenolate mofetil (MMF) as posttransplant immunosuppressive agents; no steroids were employed. The early postoperative course was uneventful, and the patient was discharged 74 days postoperatively. He received epirubicin at a dose of $10 \mathrm{mg} / \mathrm{m}^{2}$ during surgery, but did not receive postoperative chemotherapy. He was followed up by abdominal ultrasonography (US) every 3 months and by abdominal CT at $1,3,6$, and 12 months after surgery, and every 6 months thereafter. The AFP and DCP levels were checked monthly. Lamivudine was administered to control HBV virus, and HBV DNA was consistently negative after transplantation. In September 2006, 22 months after LDLT, he visited a nearby hospital with a chief complaint of discomfort on swallowing. A pedunculated polyp was found in the hypopharynx (Fig. 2a), and biopsy revealed HCC metastasis. Cervical CT revealed a pharyngeal polyp on the right side of the epiglottis; also, faint fluorodeoxyglucose (FDG) accumulation was recognized, consistent with a pharyngeal polyp on FDG positron emission tomography (PET)-CT examination (Fig. 2b, c). Polypectomy was performed on October 2006. Histological examination revealed that the tumor cells were positive for anti-hepatocyte antigen staining and a diagnosis of metastasis of $\mathrm{HCC}$ was made (Fig. 2d, e). He was administered tegafur/gimeracil/oteracil (TS-1) after polypectomy. Two years after pharyngeal polypectomy, recurrence in neck lymph nodes was detected (Fig. 2f, g), and neck lymph node dissection was performed. Recurrence subsequently occurred three times in the graft liver, and local treatment with TACE and radiofrequency ablation therapy was performed. The patient was started on oral sorafenib 3 years ago, is still alive 12 years and 10 months after recurrence of pharyngeal metastasis, and is now a tumor-free outpatient in good health continuing to take a low dose of sorafenib (Fig. 3).

\section{Discussion}

Liver transplantation is the only curative treatment for HCC associated with severe liver cirrhosis [15-17]. The critical shortage of deceased donor organs has led to the rapid development of LDLT in Eastern countries, including Japan, Korea, and China. And in contrast to deceased donor liver transplantation, recipient selection for LDLT is not limited by organ allocation systems. Subsequently, many centers have developed expanded center-specific criteria
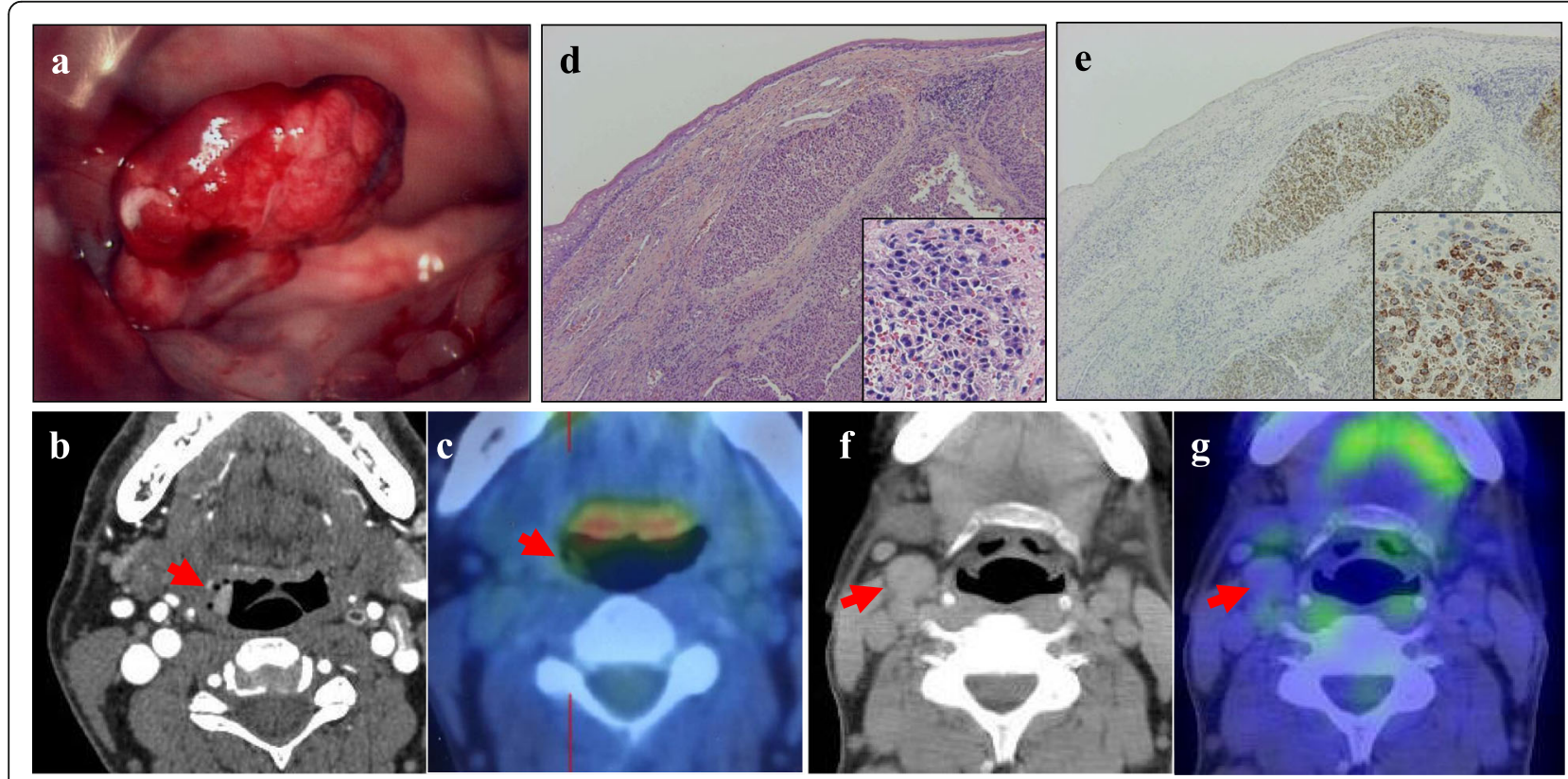

Fig. 2 Pharyngeal metastasis and cervical lymph node metastasis following living-donor liver transplantation for hepatocellular carcinoma (HCC). a Macroscopic findings of a pedunculated polyp-shaped pharyngeal metastatic lesion. b Cervical computed tomography (CT) revealing a pharyngeal polyp on the right side of the epiglottis. $\mathbf{c}$ Faint fluorodeoxyglucose (FDG) accumulation consistent with the pharyngeal polyp as observed using FDG positron emission tomography (PET)-CT. $\mathbf{d}$ Histological examination showing polygonal dysplastic epithelial cells with a trabecular or pseudotubular structure that had proliferated under the mucous membrane covered with the squamous epithelium. e These tumor cells stained positively for antihepatocyte-specific antigen and were diagnosed as indicative of HCC metastasis. $\mathbf{f}$ Cervical CT showing regional neck lymph node swelling at 2 years after pharyngeal polypectomy. $\mathbf{g}$ PET-CT scan indicating that there was almost no FDG accumulation in the enlarged cervical lymph node 


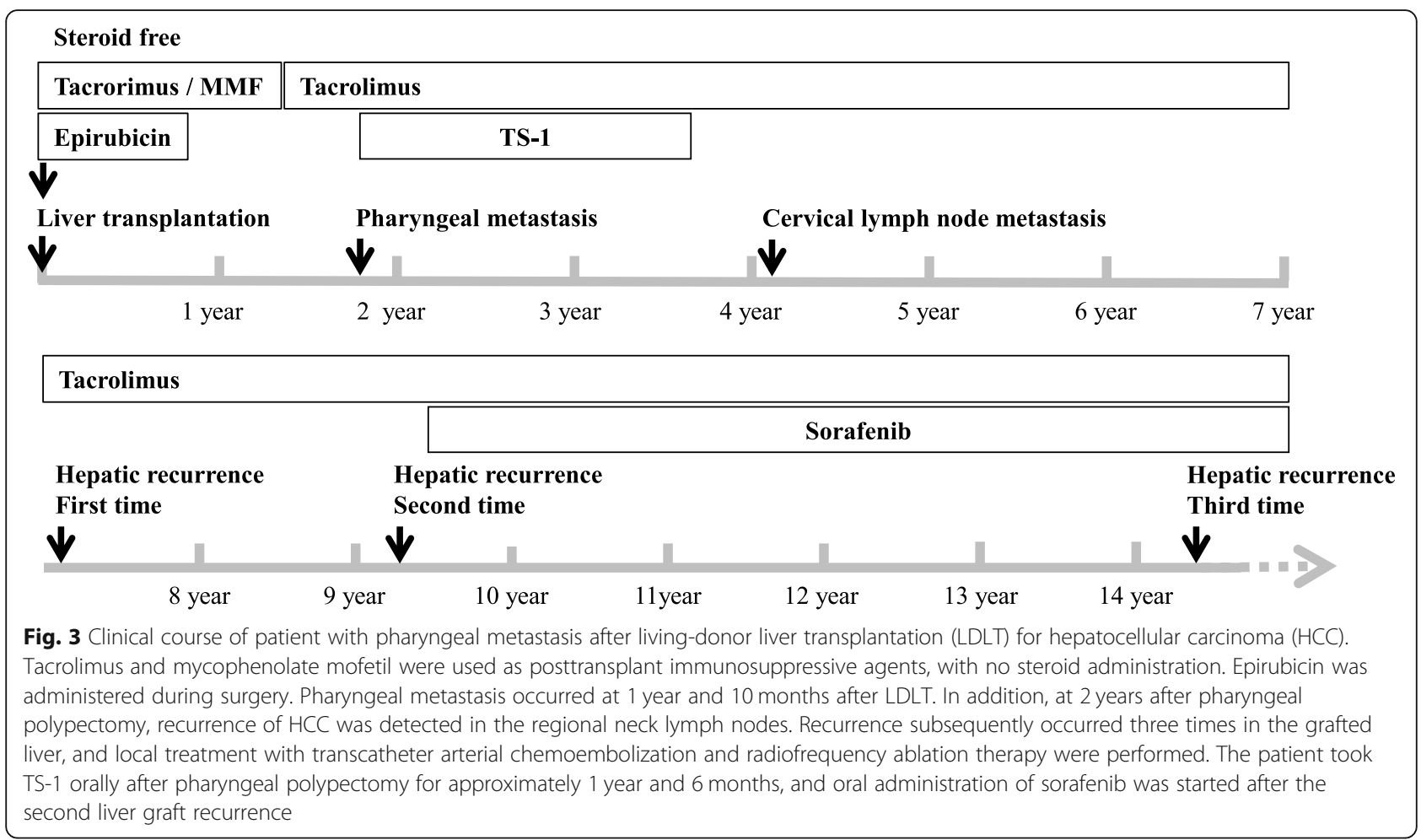

with acceptable results, including the University of California San Francisco criteria, Extended Toronto criteria, and Kyoto criteria and others [18-24].

A major issue with liver transplantation for $\mathrm{HCC}$ is that recurrence of HCC is associated with a high risk of death within a short time. The prognosis after recurrence is very poor, with reported median survival times ranging from 9 to 19 months [4, 7-11]. No effective postoperative adjuvant chemotherapy for $\mathrm{HCC}$ after liver transplantation has been established. To date, the best outcomes have been achieved by limiting the indications for transplantation according to tumor status. The Milan criteria have become the global standard guidelines for liver transplantation for HCC. Nevertheless, rates of recurrence of HCC within the Milan criteria after liver transplantation have been reported to be 1.6-13\% [1-6].

The most commonly reported initial sites of local recurrence after liver transplantation for $\mathrm{HCC}$ are the grafted liver (15\%), lung (20-30\%), bone (20-25\%), abdominal lymph node (15\%), and adrenal glands (5\%) $[2-4,10,25]$. However, the rate of initial recurrence in multiple sites was reported to be approximately $40 \%$ when systemic recurrence is promoted by circulating tumor cells; solitary recurrence is very rare, except at those sites $[2,9,10,25]$. There are seven published cases of pharyngeal metastasis from HCC, which are summarized along with our case in Table 1 [26-32]. The reports all describe male patients with a median age of 70 years (range 49-71 years). Four cases of synchronous metastasis and four cases of metachronous metastasis have been reported. The time between the first treatment and pharyngeal metastasis was $17-58$ months in cases of metachronous metastasis. Five patients, including our case, underwent surgery for pharyngeal metastases. The prognosis for all cases except ours was poor; four died within 1 year, two underwent difficult curative treatment, and one experienced multiple recurrences of pharyngeal metastasis at 1 year after surgery [28-32]. Our report is the second to describe solitary recurrence in the pharyngeal region after liver transplantation and includes the longest surviving case of HCC with pharyngeal metastasis.

The mechanism of metastasis to the pharyngeal region is controversial, although it has been speculated that there are two main pathways: tumor cells may circulate through the vena cava and be distributed to the pharyngeal region via the arterial systemic circulation, or may reach the head and neck by bypassing the lungs, possibly through the portal-vertebral venous plexus (Batson's theory) [33]. The vertebral venous plexus consists of the internal vertebral venous system distributed around the spinal canal, the external vertebral venous plexus distributed in front of the vertebral body, and the vertebral vein that anastomoses both of those sites. This plexus communicates with the intercostal vein and the azygos vein in each site. In the head and neck region, the plexus communicates with the pterygium venous plexus, cavernous venous plexus, and pharyngeal venous plexus around the nasal and paranasal 
Table 1 Characteristics of patients with pharyngeal metastasis from hepatocellular carcinoma

\begin{tabular}{|c|c|c|c|c|c|c|c|c|c|c|}
\hline Case & $\begin{array}{l}\text { Author, year } \\
\text { (reference) }\end{array}$ & Age & Sex & $\begin{array}{l}\text { Treatment for } \\
\text { primary HCC }\end{array}$ & $\begin{array}{l}\text { Maximum } \\
\text { size of } \\
\text { primary } \\
\text { HCC }(\mathrm{cm})\end{array}$ & $\begin{array}{l}\text { Number } \\
\text { of } \\
\text { primary } \\
\text { HCC }\end{array}$ & $\begin{array}{l}\text { Histopathology } \\
\text { of primary HCC }\end{array}$ & $\begin{array}{l}\text { Interval from } \\
\text { primary HCC } \\
\text { to pharyngeal } \\
\text { metastasis }\end{array}$ & $\begin{array}{l}\text { Treatment } \\
\text { for } \\
\text { metastasis }\end{array}$ & Outcome \\
\hline 1 & Ciriza,1996 [26] & 71 & M & None & 2.4 & 1 & Unknown & 3 years & Operation & Died after 8 months \\
\hline 2 & Llanes, 1996 [27] & 71 & M & None & 8 & 1 & Unknown & Synchronous & Operation & Died after 10 months \\
\hline 3 & Oida, 2005 [28] & 59 & M & Hepatectomy & 3 & 1 & Moderate & Synchronous & $\begin{array}{l}\text { Operation } \\
\text { and radiation }\end{array}$ & Died after 8 months \\
\hline 4 & Nagano, 2008 [29] & 73 & M & $\begin{array}{l}\text { Hepatectomy, } \\
\text { TAE, RFA }\end{array}$ & 3 & 1 & Unknown & 4 years 10 months & Operation & $\begin{array}{l}\text { Alive for } 1 \text { year with } \\
\text { multiple instances of } \\
\text { recurrence in the } \\
\text { remnant liver }\end{array}$ \\
\hline 5 & Kattepur, 2014 [30] & 70 & M & None & 1.9 & 1 & Unknown & Synchronous & None & - \\
\hline 6 & Guo, 2015 [31] & 50 & M & TAE & $\begin{array}{l}\text { Large, } \\
\text { diffuse }\end{array}$ & 1 & Unknown & Synchronous & Radiation & - \\
\hline 7 & Lou, 2019 [32] & 45 & M & $\begin{array}{l}\text { Liver } \\
\text { transplantation }\end{array}$ & 4 & 1 & Unknown & $\begin{array}{l}1 \text { year } \\
5 \text { months }\end{array}$ & Radiation & Died after 3 months \\
\hline 8 & Present case & 49 & M & $\begin{array}{l}\text { Liver } \\
\text { transplantation }\end{array}$ & 2.4 & Multiple & Well-moderate & $\begin{array}{l}1 \text { year } \\
10 \text { months }\end{array}$ & Operation & $\begin{array}{l}\text { Alive for } 12 \text { years } \\
10 \text { months }\end{array}$ \\
\hline
\end{tabular}

HCC hepatocellular carcinoma, $M$ male, TAE transarterial embolization, RFA radiofrequency ablation therapy

sinuses [34]. As there is no venous valve in the vertebral vein, the blood is thought to easily flow backward when the intrathoracic pressure or abdominal pressure rises [33]. HCC metastasis through the portal vein is considered to be common, such that tumor cells that have entered the vertebral vein plexus from the portal vein flow back to the pharyngeal venous plexus due to an increase of intraperitoneal pressure, and metastasize to the pharynx [33-35]. In this case, metastasis first occurred as a pharyngeal polyp, and recurrence occurred in the regional lymph node on the same side 2 years later. During this time, metastasis to other organs, including the lungs, did not occur; thus, it was strongly suspected that it had spread to the pharynx via the vertebral vein plexus of Baston. In 2005, Oida et al. reviewed 10 cases of HCC with pharyngeal metastasis (non-English articles included) [28]. In addition, Hou et al. reported 30 cases of HCC metastasis in the gingival region [36]. Collectively, these cases imply that oral cavity and nasopharyngeal metastasis via the portal-vertebral venous plexus represent a primary HCC metastatic pathway.

The Milan criteria are based on the size and number of HCCs. In addition to tumor size and number, the grade of histological differentiation, microvascular invasion, and underestimation of HCC burden based on preoperative imaging are reported to be associated with recurrence $[2,4,37,38]$. Furthermore, there is an increased desire for further information on tumor biology and surrogates of tumor biology when determining transplant suitability. Consequently, some transplantation centers include tumor markers in their patient evaluations, such as AFP and DCP, the levels of which are correlated with HCC recurrence rate $[2,20,39]$. The
HCC response to pretransplant locoregional therapy is an important surrogate marker for survival, as well as an indicator of tumor biology. Some authors reported that the 5-year overall survival rate and recurrence rate were significantly associated with pretransplant treatment for HCC $[40,41]$. In this case, pretransplant TACE for HCC resulted in a partial response, small multiple welldifferentiated HCCs that appeared to represent multicentric occurrence were observed during pathological examination, and the DCP level was high preoperatively. Therefore, this case fell within the Milan criteria based on preoperative imaging, but the risk of recurrence was considered high.

Even if the vertebral vein system develops as a collateral pathway, this does not manifest in any specific symptom, and its recognition as a transportal-vertebral metastatic pathway remains poor. In addition, metastasis in pharyngeal regions is difficult to detect because such regions represent the border between the head and chest on CT examinations. Metastasis in pharyngeal regions may be missed by common follow-up imaging procedures, such as US and CT, such that recurrence may be discovered only after metastasis to other sites. Early detection is the only factor associated with effective treatment after recurrence. Careful follow-up involving the analysis of tumor markers and imaging analysis of frequent metastatic recurrence sites, including the pharyngeal and cervical regions, are important, especially in high-risk patients.

Over the last decade, we have significantly improved our understanding of the molecular landscape of HCC [42]. Numerous studies have investigated the utility of molecular biomarkers, such as DNA alterations, to predict outcomes in patients following liver transplantation 
for HCC [42]. Circulating miRNA has emerged as one of the most attractive tools for the early diagnosis of cancers [42-44]. Some authors have reported that miRNA markers were useful predictors of HCC recurrence after liver transplantation [42, 45-47]. In the near future, it is expected that the understanding of tumor biology will advance through further analysis of these molecular mechanisms, facilitating individual risk stratification for HCC patients who will benefit from liver transplantation [42].

The concept of oligorecurrence, introduced by Hellman and Weichselbaum in 1995, suggests that survival is improved by aggressive local treatment depending on the number and location of recurrent tumors [48]. Extrahepatic recurrence of HCC often occurs at local sites after liver resection, and survival can be prolonged by surgical resection in such cases $[49,50]$. Even after liver transplantation, prolongation of survival can be expected if radical resection is performed for local recurrence [4, 6, 8, 10, 11, 13]. Although there are no strict surgical indications for HCC recurrence after liver transplantation, the recurrence time following liver transplantation is $12-24$ months or more; the prognosis of surgery for recurrence is good $[4,10,13]$. Other prognostic factors have been revealed, such as an AFP level of $100 \mathrm{ng} / \mathrm{ml}$ or greater, bone metastasis, three or more tumors, and tumor size at the time of recurrence $[8,10,11,13]$. About $10-23 \%$ of patients with recurrence survive for a long time after surgical therapy $[6,8,51]$. The median survival of unresectable cases was reported to be $5-15$ months, while that of resectable cases with local recurrence was reported to be 28-65 months; cases of long-term survival after resection of the grafted liver, lung, and adrenal metastasis have also been reported [52-55].

The factor responsible for the favorable clinical course in our case is thought to be that surgery could be performed easily to treat pharyngeal recurrence because of the pedunculated polyp-like shape at the site of recurrence, and radical resection of subsequent lymph node recurrence was possible. In addition, we used a steroid-free postoperative immunosuppressant regimen. After recurrence of HCC, TS- 1 and sorafenib were used as antitumor agents. Several studies have indicated that immunosuppressant therapy including steroid can impact HCC recurrence after liver transplantation [56]. The mammalian target of rapamycin (mTOR) inhibitors sirolimus and everolimus have been reported to be effective as immunosuppressants after liver transplantation for HCC $[57,58]$. However, data on the utility of mTOR inhibitors for treating HCC recurrence after liver transplantation remain scarce [48].

Recently, new anticancer and molecular targeted drugs, such as sorafenib, regorafenib, lenvatinib, ramucirumab, and nivolumab, have been clinically applied to treat HCC.
The efficacy of these drugs for treating recurrence after liver transplantation for HCC has been studied; several reports indicated prolongation of survival, but there is no established therapeutic regimen and there is some concern regarding adverse effects on liver function [59-62]. Clinical trials of chemotherapy for patients with HCC recurrence and/or postoperative adjuvant chemotherapy for patients at high risk of recurrence after liver transplantation are required [63].

\section{Conclusion}

In summary, we have reported a rare case of pharyngeal metastasis following LDLT for HCC. The cervical region must be recognized as a primary site of extrahepatic metastasis of HCC via the portal-vertebral venous plexus. Even with recurrence in the pharyngeal region, patients can achieve long-term survival, as in the present case. Early diagnosis of recurrence via careful periodic follow-up examinations of the cervical to nasopharyngeal region, together with frequent sites of metastatic recurrence such as the lungs, grafted liver, adrenal glands, bone, and abdominal lymph nodes, is required. At present, there is no established immunotherapy or adjuvant chemotherapy after liver transplantation that suppresses HCC recurrence. In addition, the effectiveness of surgical treatment for the oligo-recurrence of HCC after liver transplantation has been reported, but there is no effective treatment for multiple recurrences. Multidisciplinary treatment with radical resection and various subsequent treatments, including immunosuppressive treatment and anti-tumor therapy, are also needed according to the patient's condition.

\section{Abbreviations \\ HCC: Hepatocellular carcinoma; LDLT: Living-donor liver transplantation; MELD: Model End-stage Liver Disease; HBV: Hepatitis B virus; CT: Computed tomography; AFP: a-Fetoprotein; DCP: Des- - -carboxy prothrombin; MMF: Mycophenolate mofetil; US: Abdominal ultrasonography; \\ FDG: Fluorodeoxyglucose; PET: Positron emission tomography; TS-1: Tegafur/ gimeracil/oteracil; mTOR: Mammalian target of rapamycin}

\section{Acknowledgements \\ The authors would like to thank Dr. Toshiki Maetani for initial treatment of pharyngeal metastases.}

\section{Authors' contributions}

$\Pi$ designed and wrote this manuscript. $\Pi$, $\mathrm{KS}$, and $\mathrm{KT}$ collected the data. $\Pi$, $\mathrm{KS}, \mathrm{KT}, \mathrm{TN}, \mathrm{JW}$, and HW are involved in the medical treatment and took care of the patient's follow-up. YT contributed to manuscript revision. All authors read and approved the final manuscript.

\section{Funding}

The authors have no funding to declare.

Availability of data and materials

All data generated or analyzed are included in this published article.

Ethics approval and consent to participate

All data were collected anonymously and with patient's consent. We performed this case report in accordance with the Declaration of Helsinki and the ethics committee of the Ehime University School of Medicine. 


\section{Consent for publication}

Written informed consent was obtained from the patient for publication of this case report.

\section{Competing interests}

The authors declare that they have no competing interests.

\section{Author details}

'Department of Hepato-Biliary-Pancreatic and Breast Surgery, Ehime University Graduate School of Medicine, Shitsukawa, Toon, Ehime 791-0295, Japan. ${ }^{2}$ Department of Surgery, Kurashiki Medical Center, Bakuro-cho, Kurashiki, Okayama 710-8522, Japan. ' Laboratory of Head and Neck Surgery, Ehime Prefectural University of Health Sciences, 543, Takoda, Tobe-cho, lyo-gun, Ehime 791-2101, Japan.

\section{Received: 5 March 2020 Accepted: 6 May 2020}

Published online: 28 May 2020

\section{References}

1. Mazzaferro V, Regalia E, Doci R, et al. Liver transplantation for the treatment of small hepatocellular carcinomas in patients with cirrhosis. N Engl J Med. 1996;334(11):693-9.

2. Todo S, Furukawa H. Japanese Study Group on Organ T. Living donor liver transplantation for adult patients with hepatocellular carcinoma: experience in Japan. Ann Surg. 2004:240(3):451-9 discussion 459-461.

3. Ito T, Takada Y, Ueda M, et al. Expansion of selection criteria for patients with hepatocellular carcinoma in living donor liver transplantation. Liver Transpl. 2007;13(12):1637-44.

4. Kornberg A, Kupper B, Tannapfel A, et al. Long-term survival after recurrent hepatocellular carcinoma in liver transplant patients: clinical patterns and outcome variables. Eur J Surg Oncol. 2010;36(3):275-80.

5. Uchiyama H, Itoh S, Yoshizumi T, et al. Living donor liver transplantation for hepatocellular carcinoma: results of prospective patient selection by Kyushu University Criteria in 7 years. HPB (Oxford). 2017;19(12):1082-90.

6. Valdivieso A, Bustamante J, Gastaca M, et al. Management of hepatocellular carcinoma recurrence after liver transplantation. Transplant Proc. 2010;42(2):660-2.

7. de' Angelis N, Landi F, Carra MC, et al. Managements of recurrent hepatocellular carcinoma after liver transplantation: a systematic review. World J Gastroenterol. 2015:21(39):11185-98.

8. Bodzin AS, Lunsford KE, Markovic D, et al. Predicting mortality in patients developing recurrent hepatocellular carcinoma after liver transplantation: impact of treatment modality and recurrence characteristics. Ann Surg. 2017;266(1):118-25.

9. Kaido T, Mori A, Ogura Y, Ogura Y, Hata K, et al. Recurrence of hepatocellular carcinoma after living donor liver transplantation: what is the current optimal approach to prevent recurrence? World J Surg. 2011;35(6): 1355-9.

10. Roayaie S, Schwartz JD, Sung MW, et al. Recurrence of hepatocellular carcinoma after liver transplant: patterns and prognosis. Liver Transpl. 2004; 10(4):534-40.

11. Fernandez-Sevilla E, Allard MA, Selten J, et al. Recurrence of hepatocellular carcinoma after liver transplantation: is there a place for resection? Liver Transpl. 2017;23(4):440-7.

12. Hong SK, Lee KW, Yoon KC, et al. Different prognostic factors and strategies for early and late recurrence after adult living donor liver transplantation for hepatocellular carcinoma. Clin Transpl. 2019;33(10):e13703.

13. Sapisochin G, Goldaracena N, Astete $\mathrm{S}$, et al. Benefit of treating hepatocellular carcinoma recurrence after liver transplantation and analysis of prognostic factors for survival in a large Euro-American series. Ann Surg Oncol. 2015:22(7):2286-94.

14. Lencioni R, Llovet JM. Modified RECIST (mRECIST) assessment for hepatocellular carcinoma. Semin Liver Dis. 2010;30(1):52-60.

15. Llovet JM, Bru C, Bruix J. Prognosis of hepatocellular carcinoma: the BCLC staging classification. Semin Liver Dis. 1999;19(3):329-38.

16. Bruix J, Sherman M. Management of hepatocellular carcinoma: an update. Hepatology. 2011;53(3):1020-2

17. Kudo M, Trevisani F, Abou-Alfa GK, et al. Hepatocellular carcinoma: therapeutic guidelines and medical treatment. Liver Cancer. 2016;6(1):16-26.
18. Takada $Y$, Ito $T$, Ueda $M$, et al. Living donor liver transplantation for patients with HCC exceeding the Milan criteria: a proposal of expanded criteria. Dig Dis. 2007;25(4):299-302.

19. Sugawara Y, Tamura S, Makuuchi M. Living donor liver transplantation for hepatocellular carcinoma: Tokyo University series. Dig Dis. 2007;25(4):310-2.

20. Soejima Y, Taketomi A, Yoshizumi T, et al. Extended indication for living donor liver transplantation in patients with hepatocellular carcinoma. Transplantation. 2007:83(7):893-9.

21. Yao FY, Xiao L, Bass NM, et al. Liver transplantation for hepatocellular carcinoma: validation of the UCSF-expanded criteria based on preoperative imaging. Am J Transplant. 2007;7(11):2587-96

22. Sapisochin G, Goldaracena N, Laurence JM, et al. The extended Toronto criteria for liver transplantation in patients with hepatocellular carcinoma: a prospective validation study. Hepatology. 2016;64(6):2077-88.

23. Limkemann AJP, Abreu P, Sapisochin G. How far can we go with hepatocellular carcinoma in living donor liver transplantation? Curr Opin Organ Transplant. 2019;24(5):644-50.

24. Lingiah VA, Niazi M, Olivo R, et al. Liver Transplantation beyond Milan criteria. J Clin Transl Hepatol. 2020;8(1):69-75.

25. Regalia E, Fassati LR, Valente $U$, et al. Pattern and management of recurrent hepatocellular carcinoma after liver transplantation. J Hepato-BiliaryPancreat Surg. 1998:5(1):29-34

26. Ciriza C, Rivero MA, de la Serna JP, et al. Hepatocellular carcinoma with metastasis to the pharyngeal lymph nodes. J Clin Gastroenterol. 1996; 23(3):243-5.

27. Llanes F, Sanz-Ortega J, Suarez B, et al. Hepatocellular carcinomas diagnosed following metastasis to the oral cavity. Report of 2 cases. J Periodontol. 1996:67(7):717-9.

28. Oida Y, Ishii M, Dowaki S, Dowaki S, Tobita K, et al. Hepatocellular carcinoma with metastasis to the phanynx: report of a case. Tokai J Exp Clin Med. 2005:30(1):31-4.

29. Nagao $Y$, Cho A, Yamamoto $H$, et al. Hepatocellular carcinoma with pharyngeal metastasis: report of a case. Surg Today. 2008;38(11):1060-2.

30. Kattepur AK, Patil DB, Krishnamoorthy N, et al. Isolated nasopharyngeal metastasis from hepatocellular carcinoma. Int J Surg Case Rep. 2014;5(3):115-7.

31. Guo S, Wang Y. A case of hepatocellular carcinoma in an elder man with metastasis to the nasopharynx. Int J Clin Exp Pathol. 2015;8(5):5919-23.

32. Lou LL, Zhang $Y$, Huang $X$, et al. Solitary nasopharynx metastasis from hepatocellular carcinoma after liver transplantation: a case report. Medicine (Baltimore). 2019 Feb;98(7):e14368. https://doi.org/10.1097/MD. 0000000000014368

33. Batson OV. The function of the vertebral veins and their role in the spread of metastases. Ann Surg. 1940;112(1):138-49.

34. Eckenhoff JE. The vertebral venous plexus. Can Anaesth Soc J. 1971;18(5):487-95.

35. Nakashima O, Sugihara S, Kage M, et al. Pathomorphologic characteristics of small hepatocellular carcinoma: a special reference to small hepatocellular carcinoma with indistinct margins. Hepatology. 1995;22(1):101-5.

36. Hou $Y$, Deng $W$, Deng $G$, et al. Gingival metastasis from primary hepatocellular carcinoma: a case report and literature review of 30 cases. BMC Cancer. 2019:19(1):925.

37. Ecker BL, Hoteit MA, Forde KA, et al Patterns of discordance between pretransplant imaging stage of hepatocellular carcinoma and posttransplant pathologic stage: a contemporary appraisal of the Milan criteria. Transplantation. 2018:102(4):648-655.

38. Shah SA, Tan JC, Mc Gilvray ID, Cattral MS, et al. Accuracy of staging as a predictor for recurrence after liver transplantation for hepatocellular carcinoma. Transplantation. 2006;81(12):1633-9.

39. Fujiki M, Takada Y, Ogura $Y$, et al. Significance of des-gamma-carboxy prothrombin in selection criteria for living donor liver transplantation for hepatocellular carcinoma. Am J Transplant. 2009;9(10):2362-71.

40. Bargellini I, Vignali C, Cioni R, et al. Hepatocellular carcinoma: $\subset$ T for tumor response after transarterial chemoembolization in patients exceeding Milan criteria-selection parameter for liver transplantation. Radiology. 2010;255(1):289-300.

41. Kim DJ, Clark PJ, Heimbach J, et al. Recurrence of hepatocellular carcinoma: importance of mRECIST response to chemoembolization and tumor size. Am J Transplant. 2014;14(6):1383-90.

42. von Felden J, Villanueva A. Role of molecular biomarkers in liver transplantation for hepatocellular carcinoma. Liver Transpl. 2020;14. https:// doi.org/10.1002/lt.25731

43. Mirzaei HR, Sahebkar A, Mohammadi M, et al. Circulating microRNAs in hepatocellular carcinoma: potential diagnostic and prognostic biomarkers. Curr Pharm Des. 2016;22(34):5257-69. 
44. Naeli P, Pourhanifeh MH, Karimzadeh MR, et al. Circular RNAs and gastrointestinal cancers: epigenetic regulators with a prognostic and therapeutic role. Crit Rev Oncol Hematol. 2020;145:102854.

45. Morita K, Shirabe K, Taketomi A, et al. Relevance of microRNA-18a and microRNA-199a-5p to hepatocellular carcinoma recurrence after living donor liver transplantation. Liver Transpl. 2016;22(5):665-76.

46. Liese J, Peveling-Oberhag J, Doering C, et al. A possible role of microRNAs as predictive markers for the recurrence of hepatocellular carcinoma after liver transplantation. Transpl Int. 2016;29(3):369-80.

47. Sugimachi $\mathrm{K}$, Matsumura $\mathrm{T}$, Hirata $\mathrm{H}$, et al. Identification of a bona fide microRNA biomarker in serum exosomes that predicts hepatocellular carcinoma recurrence after liver transplantation. $\mathrm{Br} J$ Cancer. 2015; 112(3):532-8.

48. Au KP, Chok KSH. Multidisciplinary approach for post-liver transplant recurrence of hepatocellular carcinoma: a proposed management algorithm. World J Gastroenterol. 2018;24(45):5081-94.

49. Tomimaru Y, Sasaki $Y$, Yamada T, et al. The significance of surgical resection for pulmonary metastasis from hepatocellular carcinoma. Am J Surg. 2006; 192(1):46-51.

50. Kobayashi S, Takahashi S, Kato Y, et al. Surgical treatment of lymph node metastases from hepatocellular carcinoma. J Hepatobiliary Pancreat Sci. 2011:18(4):559-66.

51. Roberts JP. Tumor surveillance-what can and should be done? Screening for recurrence of hepatocellular carcinoma after liver transplantation. Liver Transpl. 2005;11(Suppl 2):S45-6.

52. Bates MJ, Farkas E, Taylor D, et al. Pulmonary resection of metastatic hepatocellular carcinoma after liver transplantation. Ann Thorac Surg. 2008; 85(2):412-5.

53. Togashi J, Sugawara Y, Aoki T, et al. Resection of lung metastases from hepatocellular carcinoma after living donor liver transplantation: report of two cases. Surg Today. 41(9):1294-7.

54. Hwang S, Kim YH, Kim DK, et al. Resection of pulmonary metastases from hepatocellular carcinoma following liver transplantation. World I Surg. 2012; 36(7):1592-602.

55. Mikulic D, Stironja I, Jadrijevic S, Skrtic A, et al. Adrenalectomy for bilateral metachronous adrenal recurrence of hepatocellular carcinoma after liver transplant: a case report. Exp Clin Transplant. 2019. https://doi.org/10.6002/ ect.2018.0257.

56. Miyagi S, Kawagishi N, Sekiguchi S, et al. The relationship between recurrences and immunosuppression on living donor liver transplantation for hepatocellular carcinoma. Transplant Proc. 2012;44(3):797-801.

57. Geissler EK, Schnitzbauer AA, Zulke C, et al. Sirolimus use in liver transplant recipients with hepatocellular carcinoma: a randomized, multicenter, openlabel phase 3 trial. Transplantation. 2016;100(1):116-25.

58. Cholongitas E, Mamou C, Rodriguez-Castro Kl, et al. Mammalian target of rapamycin inhibitors are associated with lower rates of hepatocellular carcinoma recurrence after liver transplantation: a systematic review. Transpl Int. 2014;27(10):1039-49.

59. Waghray A, Balci B, El-Gazzaz G, et al. Safety and efficacy of sorafenib for the treatment of recurrent hepatocellular carcinoma after liver transplantation. Clin Transpl. 2013;27(4):555-61.

60. lavarone M, Invernizzi F, Czauderna C, et al. Preliminary experience on safety of regorafenib after sorafenib failure in recurrent hepatocellular carcinoma after liver transplantation. Am J Transplant. 2019;19(11):3176-84.

61. Gomez-Martin C, Bustamante J, Castroagudin JF, et al. Efficacy and safety of sorafenib in combination with mammalian target of rapamycin inhibitors for recurrent hepatocellular carcinoma after liver transplantation. Liver Transpl. 2012;18(1):45-52.

62. DeLeon TT, Salomao MA, Agel BA, et al. Pilot evaluation of PD-1 inhibition in metastatic cancer patients with a history of liver transplantation: the Mayo Clinic experience. J Gastrointest Oncol. 2018:9(6):1054-62.

63. Sanduzzi-Zamparelli M, Diaz-Gonzalez A, Reig M. New systemic treatments in advanced hepatocellular carcinoma. Liver Transpl. 2019;25(2):311-22.

\section{Publisher's Note}

Springer Nature remains neutral with regard to jurisdictional claims in published maps and institutional affiliations.

Ready to submit your research? Choose BMC and benefit from:

- fast, convenient online submission

- thorough peer review by experienced researchers in your field

- rapid publication on acceptance

- support for research data, including large and complex data types

- gold Open Access which fosters wider collaboration and increased citations

- maximum visibility for your research: over $100 \mathrm{M}$ website views per year

At BMC, research is always in progress.

Learn more biomedcentral.com/submissions 